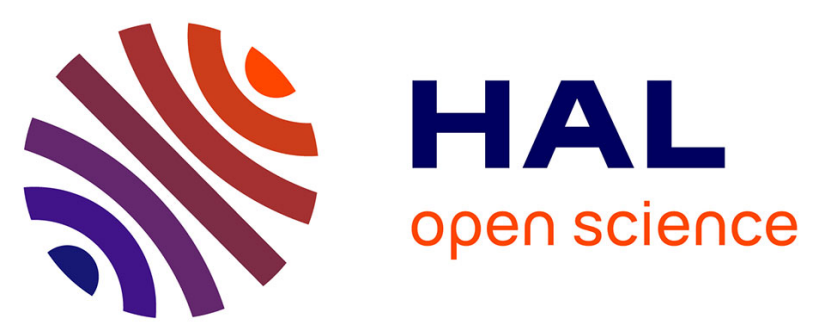

\title{
STATISTICAL ANALYSIS OF ATOM-PROBE DATA (II) : THEORETICAL FREQUENCY DISTRIBUTIONS FOR PERIODIC FLUCTUATIONS AND SOME APPLICATIONS
}

\author{
P. Auger, A. Menand, D. Blavette
}

\section{To cite this version:}

P. Auger, A. Menand, D. Blavette. STATISTICAL ANALYSIS OF ATOM-PROBE DATA (II) : THEORETICAL FREQUENCY DISTRIBUTIONS FOR PERIODIC FLUCTUATIONS AND SOME APPLICATIONS. Journal de Physique Colloques, 1988, 49 (C6), pp.C6-439-C6-444. 10.1051/jphyscol:1988675 . jpa-00228172

\section{HAL Id: jpa-00228172 https://hal.science/jpa-00228172}

Submitted on 1 Jan 1988

HAL is a multi-disciplinary open access archive for the deposit and dissemination of scientific research documents, whether they are published or not. The documents may come from teaching and research institutions in France or abroad, or from public or private research centers.
L'archive ouverte pluridisciplinaire HAL, est destinée au dépôt et à la diffusion de documents scientifiques de niveau recherche, publiés ou non, émanant des établissements d'enseignement et de recherche français ou étrangers, des laboratoires publics ou privés. 
STATISTICAL ANALYSIS OF ATOM-PROBE DATA (II) : THEORETICAL FREQUENCY DISTRIBUTIONS FOR PERIODIC FLUCTUATIONS AND SOME APPLICATIONS

\author{
P. AUGER, A. MENAND and D. BLAVETTE \\ Laboratoire de Microscopie Ionique, CNRS UA-808, Faculté des Sciences \\ de Rouen, BP 118, F-76134 Mont-Saint-Aignan Cedex, France
}

\begin{abstract}
A statistical model is proposed in order to predict the concentration histograms used for the interpretation of atom-probe analyses. This second part is devoted to systems which involve periodic fluctuations.

This new statistical tool then, is used for the interpretation of concentration profiles in a decomposed duplex stainless steel. The attraction of concentration histograms is also discussed in the case of the precipitation in a Titanium base alloy.
\end{abstract}

\title{
I - INTRODUCTION
}

This work constitutes the second part of the previous paper. First, a tentative method is proposed for predicting the frequency distribution for periodic concentration fluctuations. A simple sinusoidal signal has been chosen for calculating the concentration histogram. Such frequency distributions have been already used for the study of spinodal decomposition in steels [1]. SASSEN et al [2] compared successfully their experimental histograms with theoretical distributions they calculated. Despite our objective is similar to that of these authors, our step is slightly different. Again, differential distributions as well as the concept of variation are introduced in order to derive the amplitude of fluctuations from the histogram features.

The second part of this paper is devoted to some experiments. We will use these statistical techniques for spinodally decomposed materials as well as for precipitation process. The first experiment concerns the decomposition of the ferrite in a duplex stainless steel. Composition histograms will also be used for the study of early stages of precipitation in a $\mathrm{Ti}$ base alloy ( $\mathrm{T} i-10 \mathrm{~V}-2 \mathrm{Fe}-3 \mathrm{Al})$.

\section{II - THEORETICAL CONSTRUCTION OF CONCENTRATION HISTOGRAMS FOR A SPINODALLX DECOMPOSED ALLOY}

Let us consider a very simple concentration signal. We will assume that the measured fluctuations along the analysis direction $(x)$ can write :

$$
C(x)=C_{0}(1+\alpha \sin 2 \pi x / \lambda)
$$

$c_{0}$ is the material composition and $\alpha$ is the modulation ratio $0<\alpha<1$.

It is easy to calculate the frequency distribution of this "pure signal" by using the first derivative of the above expression :

$$
d C=c_{0} \cdot \frac{2 \pi}{\lambda} \cdot \sqrt{\alpha^{2}-\left(c / c_{0}-1\right)^{2}} d x
$$

The probability to observe the concentration with a value close to $C$ within dC is proportional to $\mathrm{dx} / \lambda$. After normalisation, the density probability $\mathrm{P}(\mathrm{C})$ can finally be written: 


$$
P(C) d C=\frac{1}{\pi} \cdot \frac{1}{\sqrt{\alpha^{2}-\left(c / C_{0}-1\right)^{2}}} \cdot \frac{d C}{C_{0}}
$$

As shown in figure 1 , the concentrations which are close to the extrema $\left(c_{0}(1+\alpha)\right.$ and $C_{0}(1-\alpha)$ ) are the most frequent amplitudes. In the opposite way, the lowest probability is observed for concentrations near the mean one $\left(C_{0}\right)$. This is the result of a very simple observation : lower is the first derivative of the concentration $\left(\frac{\mathrm{dC}}{\mathrm{dx}}\right)$ higher should be the probability to observe such a composition amplitude.

In order to work on a more realistic signal, we shall now introduce some statistical fluctuations. There is a back ground noise which superimposes to the ideal concentration profile. This leads to a dispersion around the ideal components of the theoretical distribution. The initial Dirac peaks turn into binomial distributions. The new frequency distribution, including the convolution terms, may be easily calculated :

$$
P^{*}(n)=\int_{C_{0}(1-\alpha)}^{C_{0}(1+\alpha)} \frac{1}{\pi C_{0}} \cdot \frac{1}{\sqrt{\alpha^{2}-\left(\frac{C}{C_{0}}-1\right)^{2}}} C^{n}(1-C)^{N-n} \frac{N !}{(N-n) ! n !} d C
$$

atoms.

$\mathrm{P}^{*}(\mathrm{n})$ is the probability to find exactly $\mathrm{n} B$ atoms in a layer which contains $\mathrm{N}$

The latter expression may be written with the help of a discrete summation. Assuming that the sampling parameter $\Delta C$ is small compared to $C_{0}, P^{*}(n)$ writes :

$$
P^{*}(n)=\frac{1}{\pi i_{0}} \cdot \frac{N !}{(N-n) ! n !} \cdot i=\sum_{i} i_{0}(1-\alpha)^{(i / s)^{n} \cdot(1-i / s)^{N-n}} \cdot \frac{1}{\sqrt{\alpha^{2}-\left(\frac{i}{i_{0}}-1\right)^{2}}}
$$

with $c \simeq i / s \quad c_{0} \simeq i_{0} / s \quad \Delta c=1 / s$

$s$ is the number of samples which is chosen for the construction of concentration histograms.

Typical histograns are proposed in figure 2 for two values of the modulation factor $(\alpha)$ and for an average concentration $\left(C_{0}\right)$ equal to 0.5 .

The existence of two maxima is detected for $\alpha=0.3$ while this is no longer possible for a lower value of the modulation factor $(\alpha-0.2)$. However, differential distributions clearly exhibit the amplitude of the sinusoidal signal $C(x)$. We recall here (previous paper) that the differential distribution is the difference between the "experimental" histogram $P^{*}(n)$ and a binomial distribution $B\left(n, C_{0}\right)$ the parameter of which is the nominal composition of the material $\left(C_{0}\right)$. Again, the variation $(V)$, that is the area of these differential histograms, is a parameter which allows the modulation factor to be evaluated (for $\alpha=0.2 ; \mathrm{V}=0.23$ and for $\mathrm{B}=0.3 ; \mathrm{V}=0.42$ ).

$$
\begin{gathered}
V=\sum_{n=0}^{N}\left|P^{*}(n)-B\left(n, c_{0}\right)\right| \quad 0 \leqslant v \leqslant 2 \\
\text { with } \quad B\left(n, C_{0}\right)=\frac{N !}{(N-n) ! n !}\left(C_{0}\right)^{n}\left(1-C_{0}\right)^{N-n}
\end{gathered}
$$




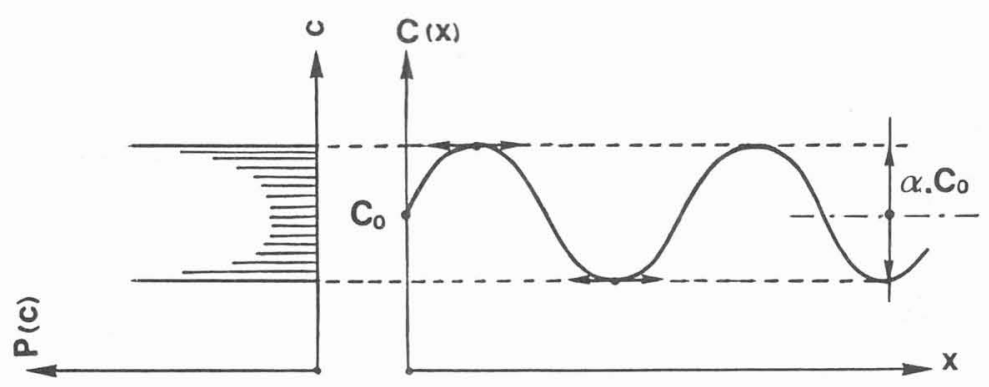

Fig. 1 : The concentration histogram of a pure sine shaped signal.
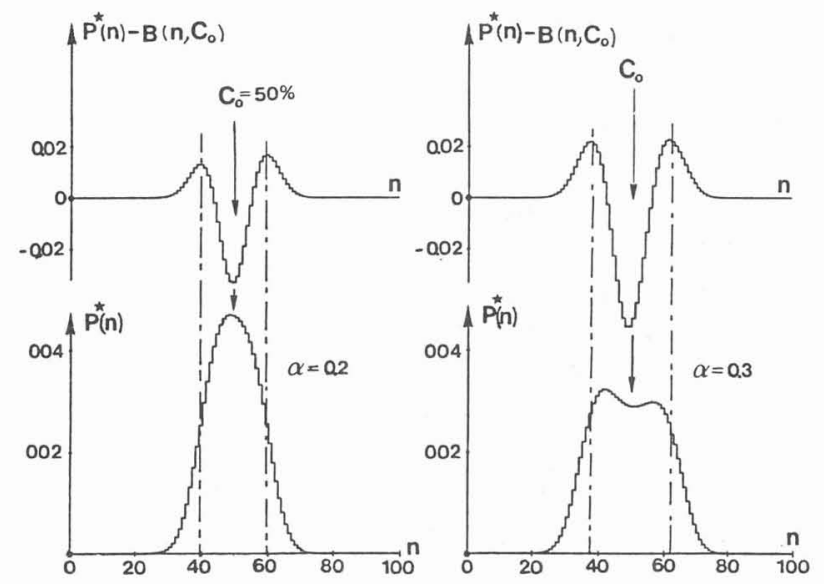

Fig. 2 : Theoretical concentration distribution for two various values of the modulation factor $(\alpha=0.2,0.3)$. The maximum and minimum amplitudes are respectively $C_{M}=60 \%, C_{m}=40 \%$ for $\alpha=0.2$ and $C_{M}=65 \%$, $C_{m}=35 \%$ for $\alpha=0.3\left(C_{0}=50 \%\right)$.

\section{ATOM PROBE ANALYSIS OF A DUPLEX STAINLESS STEEL}

During long-term low-temperature $\left(300\right.$ to $\left.400^{\circ} \mathrm{C}\right)$ aging, the ferrite matrix of duplex stainless steels decomposes into a fine scale mixture of chromium enriched phase $\alpha^{\prime}$ and an iron-rich phase $\alpha$ [3]. A similar transformation occurs in ternary alloys iron-chromium-X that spinodally decompose $[4,5]$.

The present work concerns the ferrite phase of a duplex stainless steel the composition of which is Fe-19.1 $\mathrm{Cr}-9.3 \mathrm{Ni}-1.2 \mathrm{Si}-0.8 \mathrm{Mn}-2.4 \mathrm{Mo}-0.034 \mathrm{C}$ (wt \%) with a ferrite level of $16 \%$. The alloy was heat treated 10000 hours at $350^{\circ} \mathrm{C}$. 

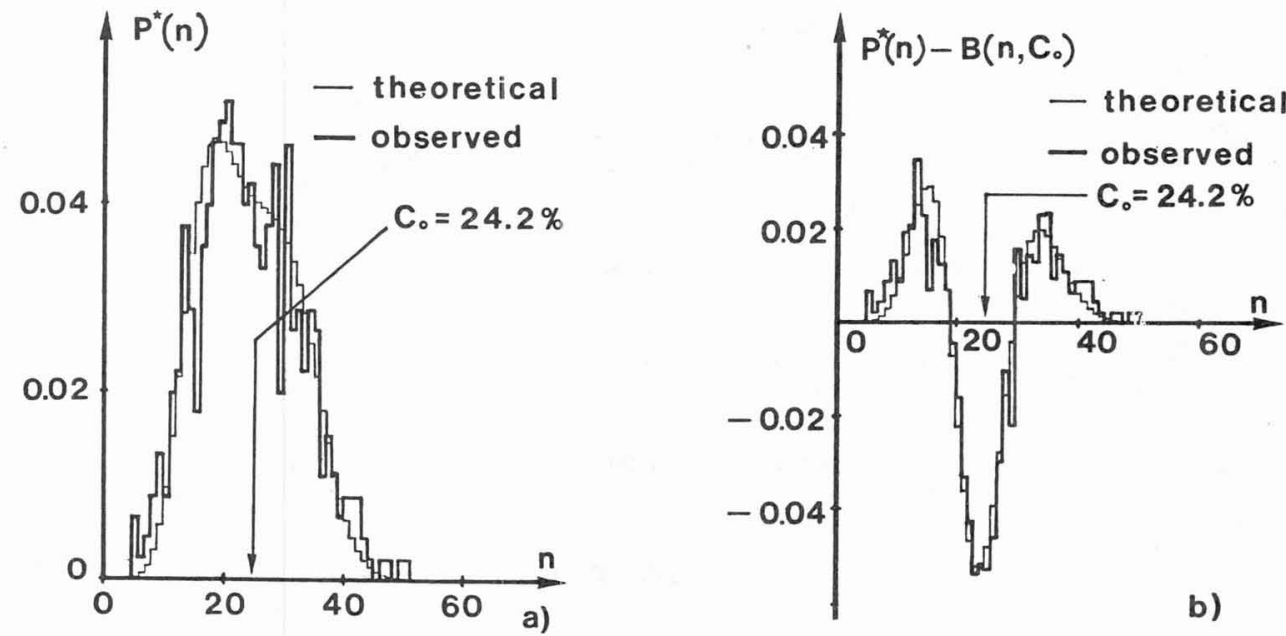

Fig. 3 : Theoretical and observed frequency distributions (a), and differential histograms (b) for chromium ( $C_{0}=24.2 \mathrm{at} \% ; \alpha=0.425$ ).

The composition profiles of chromium obtained for 45000 detected ions showed a roughtly waving aspect confirmed by a clearly periodic auto-correlation curve. In order to test the above model, we have drawn the frequency distribution chart for chromium ( 100 ions per layer) and the related differential distribution (Fig. 3). The area of this diagram, namely the variation $v$, allows the modulation factor $\alpha$ to be determined. The theoretical development described above has been used to calculate the variation $v$ for various values of $\alpha\left(C_{0}=24.2 \%\right)$. As shown in table 1 , the variation increases monotonically with the amplitude of fluctuations. For a variation close to $V=0.725$, one finds $\alpha=0.425$.

\begin{tabular}{|c|c|c|c|c|c|c|c|c|c|c|c|}
\hline$\alpha$ & 0.062 & 0.125 & 0.250 & 0.350 & 0.400 & 0.425 & 0.450 & 0.500 & 0.600 & 0.700 & 0.750 \\
\hline $\mathrm{V}$ & 0.020 & 0.090 & 0.340 & 0.585 & 0.680 & 0.725 & 0.790 & 0.895 & 1.070 & 1.200 & 1.235 \\
\hline
\end{tabular}

Table 1. The variation $V$ as a function of the modulation factor $\alpha$.

Fig. 3 shows the theoretical bar charts $P^{*}(n)$ and $P^{*}(n)-B\left(n, c_{0}\right)$ built for $\alpha=0.425$. The mean chromium concentration of the ferrite phase is $C_{0}=24.2 \%$ (at). These histograms clearly exhibit the very good agreement between both the experimental distribution and the predictions. A chi squared test confirms this observation.

It is important to notice that the concept of variation provides a reproducible way to determine the amplitude of noisy sine-like concentration profiles which are often observed in spinodally decomposed alloys. In our example the extrema were found to be close respectively to $14 \mathrm{at} \%$ and $34 \mathrm{at} \%$. These extrema may be interpreted as the chromium content of the $\alpha$ and $\alpha^{\prime}$ phases during aging.

\section{ATOM PROBE STUDY OF A Ti-10wt\%V-2wt\%Fe-3wt\%Al}

The Ti-10V-2Fe-3Al alloy is an industrial alloy mainly used for making structural components of aircraft. After quenching from the $\beta$ field, the alloy is composed of two phases : a BCC $\beta$ matrix and an hexagonal athermal $\omega$ phase the composition of which is the same as the matrix. During aging at $300^{\circ} \mathrm{C}$, precipitates of an isothermal $\omega$ phase form either by transformation of the athermal $\omega$ phase or directly. After a few days at $300^{\circ} \mathrm{C}$ small needle shaped $\alpha$ phase precipitates are visible by TEM [6].

The purpose of the atom-probe study combined with TEM observations is to follow the precipitation of the isothermal $\omega$ and $\alpha$ phases. Preliminary results were presented last year [7]. The isothermal $\omega$ phase appears as titanium enriched and v, Fe, Al depleted while the $\alpha$ phase is aluminium enriched. 


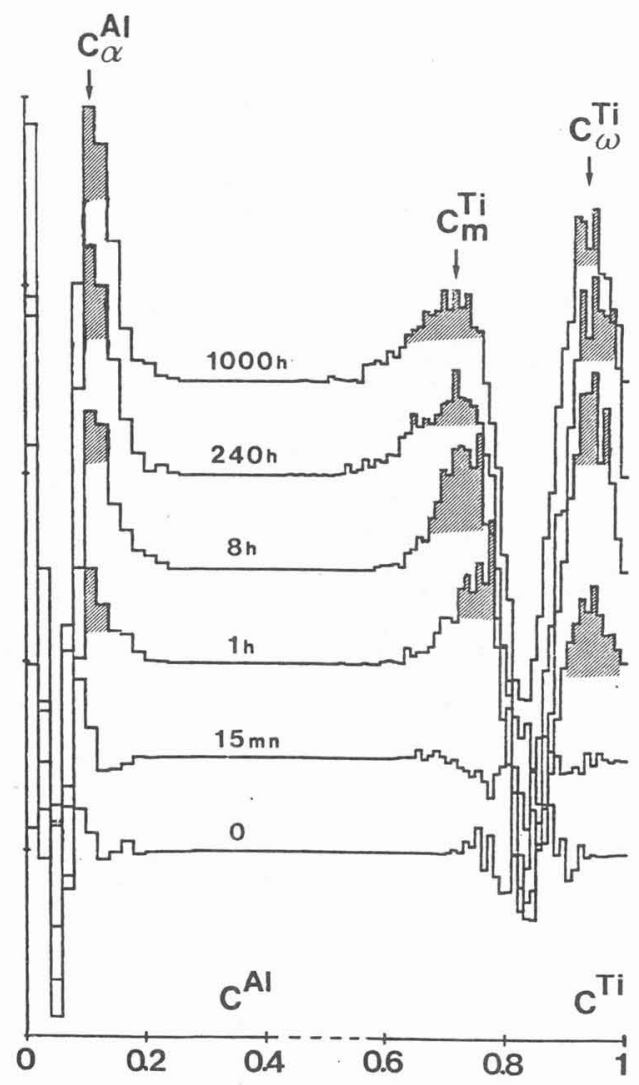

Fig. 4 : Differential distributions related to aluminium (left part) and titanium (right part) as as a function of the aging times at $300^{\circ} \mathrm{C}$ (Ti-10V-2Fe-3A1).

It is quite easy to determine the composition and the volume fraction of $w$ phase directly from the concentration profiles (lever rule). In contrast, the features of $\alpha$ phase are more difficult to be derived. $\alpha$ phase precipitates are only visible on the profiles for the longest aging times. The use of differential distributions is an elegant way to follow the precipitation of both phases $\alpha$ and $\omega$.

Fig. 4 gives the differential distributions of aluminium (left part) and titanium (right part) obtained from the concentration profiles for different aging times ranging from $t=0$ (quenched state) to $1000 \mathrm{~h}$ at $\mathrm{T}=300^{\circ} \mathrm{C}$. Each curve is calculated over more than 50000 atoms .

The curves related to Ti clearly exhibit the evolution of $\omega$ and $\beta$ phase composition $\left(C_{\omega}^{\top}{ }^{i}, C_{m}^{i}\right)$ during aging. The peak concerning $\omega$ which is located within $94 \%$ only appears for 1h. After this stage the composition of $\omega$ precipitates is nearly constant while the $\beta$ one decreases slowly towards the equilibrium value. The evolution of the variation, namely the differential distribution area, agrees with the observed volume fraction increase of the $\omega$ phase.

The differential distribution of aluminium points out the appearance of a peak close to $10 \%$ as early as $1 \mathrm{~h}$. This clearly indicates that $\alpha$ phase initially forms at the same time the $\omega$ phase composition change occurs. 
CONCLUSION

Concentration histograms constitute a powerful tool for the statistical analysis of concentration profiles. Such a treatment allows valuable information to be dexived. For sine-shaped concentration profiles, it is possible to get analytically the amplitude of fluctuations despite the sampling noise. The method we described provides a simple way to calculate theoretical distributions for a given set of parameters, namely the mean concentration of the material and the amplitude of fluctuations.

The concept of differential distribution has been introduced. It has been shown that the area of such an histogram (the variation) is a measurement of the statistical distance between the observation and the random state : the variation is clearly connected with the amplitude of fluctuations. As the number of desorbed layers in experiments is not infinite, the variation (V) for small deviations must be used with prudence. Because of statistical fluctuations in the data, a random solid solution will lead to a small but finite value of $V$. This is specially pronounced for those channels $(n)$ for which $P(n)$ is close to $B(n)$. A chi-squared test is therefore highly desirable in order to distinguish between systematic and random trends. For larger deviations from randomness and for a reasonable number of samples $(>1000)$, the superestimation of the actual statistical distance (V) should become negligible. Random fluctuations from one channel to another in differential distributions may even statistically cancel.

Frequency distributions have been applied to the study of the spinodal decomposition in a duplex stainless steel. The results demonstrate that the observed histograms for chromium in the ferrite phase are very close to that predicted.

Frequency distributions are also well suitable for the study of early stages of precipitation or clustering. By performing a chi-squared test between the observed histogram and a binomial distribution, it is possible to detect a deviation from randomness or the presence of very fine clusters [8]. In this paper, differential distributions have been shown to be an elegant manner to follow the precipitation process in a titanium base alloy. The observed histograms clearly revealed that both $\omega$ precipitates and $\alpha$ phase begin to be detected in concentration profiles as soon as $t=1 \mathrm{~h}$ at $\mathrm{T}=300^{\circ} \mathrm{C}$.

\section{REFERENCES}

[1] S.S. BRENNER, P.P. CAMUS, M.K. MILLER and A. SOFFA, Acta. Met., 32, (1984) pp. 1217-1227

[2] T.J. GODFREY, M.G. HETHERINGTON, J. SASSEN, G.D.W. SMITH (These proceedings)

[3] M.K. MILLER and J. BENTLEY, Proc. of 33rd IFES, J. de Phys., Colloque c7-11, t47, (1986) PP. $233-244$

[4] S.S. BRENNER, M.K. MILLER and W.A. SOFFA, Scripta Met., 16 (1982) 831

[5] F. ZHU, H. WENDT and P. HAASEN, Scripta Met., 16 (1982) 1175

16] M.H. CAMPAGNAC, Thèse de Doctorat de 1'Université Pierre et Marie CURIE, PARIS, (1988)

[7] L. HADJADJ, A. MENAND and C. MARTIN, J. de Phys, 48-C6 (1987) 293

[8] D. BLAVETTE, P. CARON and T. KHAN, Scripta Met, 20, (1986) 1395 